\title{
Application of Eigenvalues and Eigenvectors in Correlating Density and Fire Properties of Some Selected Woods in South-East Nigeria
}

\author{
Vincent Nwalieji Okafor, Igwebuike Enweonye, and Patrick Ugochukwu Umennadi
}

\begin{abstract}
Data sourced from literature for wood density (WD) and fire properties for fifteen Nigerian woods were analysed. The fire properties are ignition time (IT), flame propagation rate (FPR), flame duration (FD), afterglow time (AGT), ash formation (AF) and limiting oxygen index (LOI). The aim was to correlate density and fire properties of wood using eigenvalues and eigenvectors. The analysis tool adopted was the statistical analysis system (SAS) where principal component and regression analyses were performed. Based on the presented data and analyses, WD was found to relate well with FPR, AGT and LOI with an adjusted R-Square $=83 \%$ while the other three parameters: IT, FD and AF constitute random noise.
\end{abstract}

Index Terms-Eigenvalues, Eigenvectors, Fire properties, Wood density, South-East Nigeria.

\section{INTRODUCTION}

Woods have multipurpose uses in the human society. They found wide application in construction of ships, boats, furniture etc. and are extensively used in buildings as well as for fuels and many other industrial applications such as, in the pulp and paper industry, forest reserves, the toothpick industry and for afforestation purposes among others [1].

Combustion / pyrolysis has been identified as the greatest factor that undermines or limits the application of woods [2]. During the combustion of a wood material, oxidation occurs which results to exothermic chemical reaction producing heat, gases, tars, char, vapour, light, volatile and various reaction products [3]-[6]. Fire starts on a flammable or combustible material when exposed to a heat source in combination with adequate supply of an oxidizer such as oxygen or oxygen-rich compound. Above the flash point of the fuel, fire sustains a rate of rapid oxidation and a chain reaction is produced which is usually termed fire tetrahedron. Fire will never exist if all these elements are not in place and in the right proportion. Once fire is sustained, the wood undergoes thermal degradation [5], [6].

In practice, pyrolysis and combustion of flammable volatile do not occur at the same time. It is important to distinguish pyrolysis from combustion. Pyrolysis which is the thermal

DOI: http://dx.doi.org/10.24018/ejers.2021.6.6.2595

Published on October 19, 2021.

Vincent Nwalieji Okafor is with the Department of Pure and Industrial Chemistry, Nnamdi Azikiwe University, PMB 5025, Awka 420007, Nigeria (e-mail: vnw.okafor@unizik.edu.ng).

Igwebuike Enweonye is with the Department of Biostatistics, AB Science Pharmaceutical (Oncology), 75008 Paris, France (e-mail: anakuogbe@yahoo.com).

Patrick Ugochukwu Umennadi is with the Department of Pure and Industrial Chemistry, Nnamdi Azikiwe University, PMB 5025, Awka 420007, Nigeria (e-mail: pu.umennadi@unizik.edu.ng) decomposition of a material takes place without an oxidizer, and hence an endothermic reaction. In the presence of an oxidizer, the products of pyrolysis undergo a rapid thermal decomposition resulting in an exothermic reaction [5], [6]. It is also known that piloted flame ignition (in which a flame gives energy to the gaseous species) usually takes place at a lower temperature than unpiloted ignition (where the volatile must achieve the necessary energy for ignition through heating alone) [1], [5], [7]. Incomplete combustion occurs when there is insufficient supply of an oxidizer resulting essentially to carbonaceous products such as carbon monoxide, char, smoke, unburnt flammable volatile and nonflammable gases [7]. The glowing process that occurs in carbonaceous char is represented in equations (1) and (2).

Obviously, the production of $\mathrm{CO}_{2}$ releases more heat than the evolution of $C O$. This is so because the combustion reaction at the carbon monoxide stage does not sustain selfpropagation due to the release of small quantity of heat at that stage but self-propagation is sustained at complete combustion reaction in which a lot of heat is evolved [8].

$$
\begin{aligned}
& C+\frac{1}{2} \mathrm{O}_{2} \stackrel{\text { heat }}{\longrightarrow} \mathrm{CO} \triangle H=-1.31 \mathrm{KJJ}_{\mathrm{mol}}{ }^{-1} \\
& \mathrm{C}+\mathrm{O}_{2} \stackrel{\text { heat }}{\longrightarrow} \mathrm{CO}_{2} \triangle H=-4.76{\mathrm{KJ} . \mathrm{mol}^{-1}}^{-1}
\end{aligned}
$$

Several factors determine the thermal property of any material. These include the chemical constitution and the environmental conditions such as temperature, pressure, draught or air flow, surface contour and orientation. The most important single factor is, of course, the chemical constitution of the material [4]. Studies on the burning characteristics of tropical woods abound [8]-[11] and especially, the relationship between wood density and moisture content. For example, Wang et al. (1984) [12] studied the variation in density and moisture content of wood and bark among twenty Eucalyptus grandis progenies. The authors reported that differences in density and moisture content among progenies were significant and variations in wood properties were largely due to genetic differences and that there was no relationship between wood density and moisture content. In agreement with their findings is the widely reported negative correlation between sapwood saturated water content and density which was asserted by Meinzer et al. (2003) [13]. Consequently, wood density and moisture content are independent variables and therefore do 
not correlate. Nonetheless, literature on the application of eigenvalues and eigenvectors in the correlation of fire properties with wood density is not well developed; hence, this study.

\section{METHODOLOGY}

The data used were published by [11], [14]. The data were generated from investigation of fire properties of fifteen Nigerian wood species from different rainforests in SouthEast, Nigeria. The selection was based on the information obtained from respondents (seasoned farmers and wood dealers) to questionnaires. The construction of the questionnaires reflected the six points modified Likert scale of strongly agree, agree, somewhat agree, somewhat disagree, disagree, strongly disagree. The density and fire properties of the woods were measured according to previous works of literature [1], [2], [8]-[11]. The data are shown in Table I: The combustion characteristics of 15 Nigerian woods showing density and fire properties in their respective international system of units.

TABLE I

Density and Fire Properties of the Woods

\begin{tabular}{|lllllllll|}
\hline S/N & Tree Species & $\begin{array}{l}\text { WD } \\
\left(\mathrm{gcm}^{-1}\right)\end{array}$ & IT (s) & $\begin{array}{l}\text { FPR } \\
\left(\mathrm{cms}^{-1}\right)\end{array}$ & FD (s) & AGT (s) & AF (\%) & LOI (\%) \\
\hline 1 & D. oliveri & 0.39 & 3.00 & 0.27 & 12.00 & 184.00 & 1.26 & 28.78 \\
2 & A. occidentale & 0.40 & 4.00 & 0.26 & 17.00 & 215.00 & 1.33 & 26.81 \\
3 & V. doniana & 0.44 & 5.00 & 0.24 & 31.00 & 267.00 & 2.38 & 27.14 \\
4 & L. griffonianus & 0.45 & 3.00 & 0.23 & 27.00 & 204.00 & 2.16 & 26.29 \\
5 & G. arborea & 0.46 & 3.00 & 0.22 & 34.00 & 166.00 & 0.26 & 27.52 \\
6 & N. alitiolia & 0.46 & 4.00 & 0.21 & 28.00 & 198.00 & 0.88 & 26.06 \\
7 & T. grandis & 0.47 & 6.00 & 0.20 & 39.00 & 99.00 & 1.12 & 29.56 \\
8 & M. indica & 0.59 & 6.00 & 0.16 & 27.00 & 70.00 & 2.14 & 28.60 \\
9 & D. regia & 0.61 & 5.00 & 0.17 & 56.00 & 172.00 & 0.36 & 26.00 \\
10 & N. laevis & 0.62 & 4.00 & 0.15 & 27.00 & 218.00 & 1.53 & 27.03 \\
11 & A. indica & 0.63 & 7.00 & 0.15 & 26.00 & 179.00 & 0.29 & 28.32 \\
12 & D. guineense & 0.71 & 8.00 & 0.15 & 33.00 & 134.00 & 0.19 & 28.21 \\
13 & T. superb & 0.75 & 3.00 & 0.18 & 28.00 & 170.00 & 0.56 & 29.75 \\
14 & M. obovate & 0.94 & 10.00 & 0.15 & 13.00 & 197.00 & 0.19 & 30.49 \\
15 & I. gabonensis & 0.97 & 9.00 & 0.15 & 19.00 & 185.00 & 0.96 & 29.93 \\
\hline
\end{tabular}

In order to gain insight to the analysis variables, the SAS procedure PROC FACTOR was employed, which used the Principal Component Analysis (PCA) [15], as default option. The eigenvalues corresponding to the principal components (eigenvectors) are arranged according to the proportion of variation of data explained by each. PCA provides an elegant dimensionality reduction as a way to reduce the complexity of a model and avoid over-fitting. PCA method informs the contributions of each principal component, to the total variance, and the eigenvectors associated with non-zero eigenvalues, of the coordinates. In practice, it is sufficient to include enough principal components that cover about 70 to 80 percent of the data variation.

Alternatively, the scree plot [16], a graph of eigenvalues, provides a tool to determine the number of factors to retain. The reduced dimension data set allows to process, analyze and interpret data in an easy way. In model selection, the residual sum of squares always get smaller as more variables are added to a model. If we aim to select the model with the smallest residual sum of squares, the model including all variables would always be selected. Mallows's $C_{p}$ addresses the issue of over-fitting. Under this criterion the optimal model is a compromise influenced by the sample size, the effect sizes of the different predictors, and the degree of collinearity between them. If $\mathrm{P}$ regressors are selected from a set of $K>P$, the $C_{p}$ statistic for that particular set of regressors is defined as:

$$
C_{p}=\frac{S S E_{p}}{S^{2}}-n+2(p+1)
$$

Where $S S E_{p}=\sum_{i=1}^{N}\left(Y_{i}-Y_{p i}\right)^{2}$ is the error sum of squares for the model with $P$ regressors;

$Y_{p i}$ is the predicted value of the $i^{t h}$ observation of $Y$ from the $P$ regressors;

$S^{2}$ is the residual mean square after regression on the complete set of $K$ regressors and can be estimated by mean square error (MSE), $n$ is the sample size. The lower the $C_{p}$ is the better the model.

A model with a larger $\mathrm{R}$-squared value means that the independent variables explain a larger percentage of the variation in the independent variable. However, this may conflict with parsimony. The adjusted R-squared value takes this into account:

$$
\operatorname{Adj} R^{2}=1-\left(1-R^{2}\right)[(n-1) /(n-p-1)]
$$

$R^{2}$ decreases if there are too many regressors in the model.

We describe other model selection criteria to be used where $n$ is the number of observations, $p$ is the number of model parameters, including the intercept, $\sigma^{2}$ is an estimate of the pure error variance from fitting the full model. The Akaike Information Criterion,

$$
A I C=n \ln (S S E / n)+2 p
$$

and, the Baysian Information Criterion,

$$
B I C=n \ln (S S E / n)+2(p+2) s-2 q^{2}
$$

Where $q=n \sigma^{2} / S S E$. These criteria represent various approaches for balancing model accuracy with parsimony. The recommendation is to use the adjusted R-squared value.

Our final goal is to estimate a regression function $f\left(X_{i}, \beta\right)$ that most closely fits $Y_{i}$ the wood density data; $X_{i}$ is the set of selected fire characteristics and $\beta$ are the parameter estimates. That is,

$$
Y_{i}=f\left(X_{i}, \beta\right)+e_{i}
$$

$e_{i}$ are random error term assumed to be normally distributed with zero mean and variance $\sigma^{2}$. For further details around regression steps we refer to [17].

\section{Data Presentation and Analysis}

Table I presents the values for wood density which ranged from 0.39 to $0.97 \mathrm{gcm}^{-1}$, ignition time $[3.00-10.00(\mathrm{~s})]$, flame propagation rate $\left(0.15-0.27 \mathrm{cms}^{-1}\right)$, flame duration [12.00-39.00(s)], afterglow time [70.00-267(s)], ash formation $(0.19-2.38 \%)$ and limiting oxygen index (26.00-30.49\%). The means and the standard deviations of the data are 0.593 (SD $\pm 0.18441), 5.333(\mathrm{SD} \pm 2.28869), 0.193(\mathrm{SD} \pm 0.04317)$, $27.800(\mathrm{SD} \pm 10.90347), 177.200(\mathrm{SD} \pm 48.17261), 1.041$ $(\mathrm{SD} \pm 0.75497)$ and $28.03267(\mathrm{SD} \pm 1.47684)$ for $\mathrm{WD}, \mathrm{IT}$, FPR, FD, AGT, AF and LOI respectively (Table II)

The Pearson Correlation Coefficient was used to check the association between wood density and fire properties. At 5\% 
TABLE II

Simple Statistics of WD and Fire Properties of Wood

\begin{tabular}{|lllllll|}
\hline Label & Variable & N & Mean & Std Dev & Minimum & Maximum \\
& & & & & & \\
\hline WD $\left(\mathrm{gcm}^{-1}\right)$ & Wood Density & 15 & 0.593 & 0.1844 & 0.39 & 0.97 \\
IT $(\mathrm{s})$ & Ignition Time & 15 & 5.333 & 2.2887 & 3.00 & 10.00 \\
FPR $\left(\mathrm{cms}^{-1}\right)$ & Flame Propagation Rate & 15 & 0.193 & 0.0432 & 0.15 & 0.27 \\
FD $(\mathrm{s})$ & Flame Duration & 15 & 27.800 & 10.9035 & 12.00 & 56.00 \\
AGT $(\mathrm{s})$ & Afterglow Time & 15 & 177.200 & 48.1726 & 70.00 & 267.00 \\
AF $(\%)$ & Ash Formation & 15 & 1.041 & 0.7550 & 0.19 & 2.38 \\
LOI $(\%)$ & Limiting Oxygen Index & 15 & 28.033 & 1.4768 & 26.00 & 30.49 \\
\hline
\end{tabular}

level of significance, we note significant positive correlation between wood density and ignition time $(\rho=0.75932$, Pvalue $=0.001)$; wood density and limiting oxygen index $(\rho$ $=0.63428, \mathrm{P}$-value $=0.0111)$. That means that the value of wood density either rises or falls with ignition time and limiting oxygen index. Further we note a significant negative correlation between wood density and flame propagation rate $(\rho=-0.79857, \mathrm{P}$-value $=0.0004)$. The interpretation is that the value of wood density decreases with the increasing value of flame propagation rate and vice versa. Ignition time is seen to have negative association with flame propagation rate ( $\rho$ $=-0.66749, \mathrm{P}$-value $=0.0066)$ and positive association with limiting oxygen index $(\rho=0.56755$, P-value $=0.0273)$. These results are displayed in Table III.

TABLE III

Pearson Correlation Coefficient of the Combustion data, $\mathbf{N}=15$, Prob $>|r|$ under Ho: Rho=0

\begin{tabular}{|c|c|c|c|c|c|c|c|}
\hline & WD & & FPR & FD & AGT & $\mathbf{A F}$ & LOI \\
\hline & 1 & 0.7593 & -0.7986 & -0.1681 & -0.1036 & -0.4515 & 0.6343 \\
\hline IT & & 1 & -0.6675 & -0.1574 & $-0.015)$ & -0.3399 & $\begin{array}{l}0.5676 \\
0\end{array}$ \\
\hline & & & $(0.0066)$ & $(0.5753)$ & $(0.4715)$ & $(0.2151)$ & $(0.0273)$ \\
\hline FPR & & & 1 & -0.1961 & 0.35589 & 0.4183 & -0.3651 \\
\hline FD & & & & $\begin{array}{l}(0.4838) \\
1\end{array}$ & $\begin{array}{c}(0.1930) \\
-0.2550\end{array}$ & $\begin{array}{l}(0.1207) \\
-0.1520\end{array}$ & $\begin{array}{l}(0.1808) \\
-0.4251\end{array}$ \\
\hline & & & & & $(0.3590)$ & $(0.5886)$ & $(0.1142)$ \\
\hline AGT & & & & & 1 & $\begin{array}{l}0.1747 \\
(0.5335)\end{array}$ & $\begin{array}{l}-0.3714 \\
(0.1729)\end{array}$ \\
\hline $\mathrm{AF}$ & & & & & & & $\begin{array}{c}-0.2829 \\
(0.369)\end{array}$ \\
\hline LOI & & & & & & & 1 \\
\hline
\end{tabular}

In other to gain insight to the analysis variables, the SAS procedure PROC FACTOR was employed using PCA as default option. Table IV shows the resulting eigenvalues of the correlation matrix presented in Table III. The eigenvalues corresponding to the principal components (eigenvectors) are arranged according to the proportion of variation of data explained by each. The first principal component explains approximately $36 \%$ while the second principal component explains approximately $25 \%$ of the total variability and so on. The cumulative variability explained by the first three principal components is approximately $80 \%$. The analysis suggests that the dimensionality can be reduced to three factors with $2.549,1.745$ and 1.277 variabilities explained by each factor respectively.

1) Model Selection: The regression step is used with the options R-square, Mallow's $C_{p}$, Akaike information criteria (AIC) and Bayesian information criteria (BIC) to select the most parsimonious model for wood density. We present these
TABLE IV

Eigenvalues of the Correlation Matrix:

Total $=7$ Average $=1$

\begin{tabular}{|lllll|}
\hline & Eigenvalue & Difference & Proportion & Cumulative \\
\hline 1 & $\mathbf{2 . 5 4 9 2 9 4 4 1}$ & $\mathbf{0 . 8 0 4 6 7 7 8 8}$ & $\mathbf{0 . 3 6 4 2}$ & $\mathbf{0 . 3 6 4 2}$ \\
2 & $\mathbf{1 . 7 4 4 6 1 6 5 3}$ & $\mathbf{0 . 4 6 7 6 1 8 0 0}$ & $\mathbf{0 . 2 4 9 2}$ & $\mathbf{0 . 6 1 3 4}$ \\
3 & $\mathbf{1 . 2 7 6 9 9 8 5 3}$ & $\mathbf{0 . 5 6 2 1 2 1 6 2}$ & $\mathbf{0 . 1 8 2 4}$ & $\mathbf{0 . 7 9 5 8}$ \\
4 & 0.71487691 & 0.33686207 & 0.1021 & 0.8980 \\
5 & 0.37801484 & 0.15493955 & 0.0540 & 0.9520 \\
6 & 0.22307530 & 0.10995183 & 0.0319 & 0.9838 \\
7 & 0.11312347 & & 0.0162 & 1.0000 \\
\hline
\end{tabular}

in Table V. Model 1 with only FPR as the regressor shows an R-sq $=0.6377$. Model 2 with FPR and LOI as regressors indicated R-sq $=0.7732$ and model 3 having FPR, AGT and LOI as regressors indicate $\mathrm{R}-\mathrm{sq}=0.8678$.

This is the most parsimonious model for wood density as beyond that point, the R-sq shows no significant changes. The AIC score rewards models that achieve a high goodness-offit score and penalizes them if they become overly complex. By itself, the AIC score is not of much use unless it is compared with the AIC score of a competing model. When fitting models, it is possible to increase the likelihood by adding parameters but doing so may result in over-fitting. The BIC resolves this problem by introducing a penalty term for the number of parameters in the model. The penalty term is larger in BIC than in AIC. BIC has been widely used for model identification in linear regression. Note that model 3 also has the lowest Mallow's $C_{p^{-}}$statistics (value $=0.8637$ ) and beyond that all models show increasing values of AIC and BIC. The parameter estimates for each model is shown to the right panel of the table.

TABLE V Model Selection Method

\begin{tabular}{|llllllllllll|}
\hline $\mathbf{N}$ & $R_{s q}$ & $C_{p}$ & AIC & BIC & INT. & IT & FPR & FD & AGT & AF & LOI \\
\hline 1 & 0.6377 & 10.555 & -62.983 & -62.384 & 1.250 & $\cdot$ & -3.411 & $\cdot$ &. &. & \\
2 & 0.7732 & 4.492 & -68.010 & -65.365 & -0.253 &. & -2.794 &. &. &. & 0.0494 \\
$\mathbf{3}$ & $\mathbf{0 . 8 6 7 8}$ & $\mathbf{0 . 8 6 4}$ & $-\mathbf{- 7 4 . 1 0 8}$ & $\mathbf{- 6 6 . 4 9 5}$ & $\mathbf{- 0 . 7 4 8}$ & & $\mathbf{- 3 . 1 6 6}$ &. & $\mathbf{0 . 0 0 1 3}$ &. & $\mathbf{0 . 0 6 1 3}$ \\
4 & 0.8751 & 2.429 & -72.961 & -62.847 & -0.659 & 0.011 & -2.843 &. & 0.0012 &. & 0.0544 \\
5 & 0.8797 & 4.155 & -71.526 & -58.772 & -0.623 & 0.011 & -2.728 &. & 0.0012 & -0.0185 & 0.0330 \\
6 & 0.8807 & 6.099 & -69.642 & -54.539 & -0.478 & 0.010 & -2.785 & -0.0007 & 0.0012 & -0.0204 & 0.0495 \\
\hline
\end{tabular}

2) Final Model: Using the information obtained from model selection we fitted the wood density to FPR, AGT and LOI using PROC REG is SAS. The resulting estimated model for WD has F-Value $=24.08$ (P-value $<0.0001)$. At 5\% level, we can reject the null hypothesis that the regression parameters are zero. Hence,

$\widehat{W D}=-0.7479-3.1663 \times F P R+0.0013 \times A G T+0.0613 \times L O I$

This model has R-Square $=87 \%$ and Adj R-Square $=83 \%$. Graphical checks for lack of fit (Figure 1) suggest no clear patterns. We conclude that our model fits well the data. This is also evident from the graph of the empirical versus the predicted values (Figure 2) which shows a narrow confidence interval. 
Fig. 1. Diagnostic checks for lack of fit

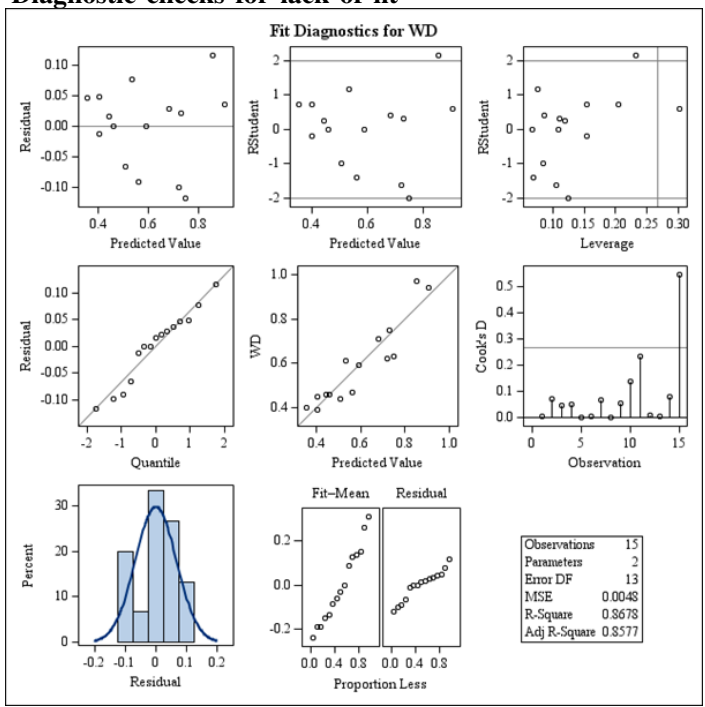

The residual plots do not show any clear pattern. The histogram shows that the error terms are normally distributed. $R$-square $=0.8678$ and very close to the Adjusted $R$ square $=0.8577$. Goodness of model fit can be trusted.

Fig. 2. Plot of empirical versus fitted Wood density data

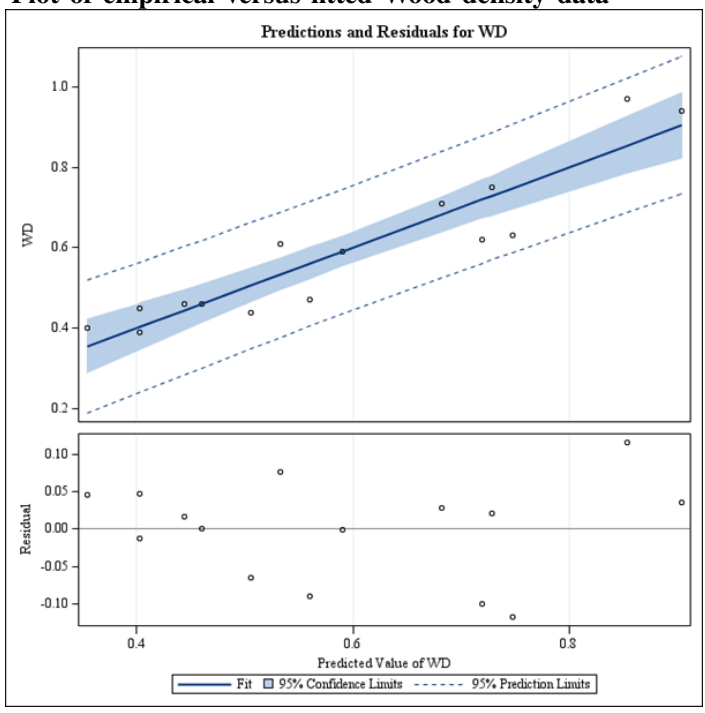

The Empirical versus the predicted WD data with $95 \%$ confidence limits in hash and $95 \%$ prediction limits in dotted lines. Beneath is the plot of residual versus predicted WD indicating no clear pattern.

\section{DisCUSSION AND CONCLUSION}

This study investigated the relationship between wood density and fire properties of fifteen Nigerian woods relying on data published in [11] and [14]. The method of principal components: Eigenvalues and Eigenvectors as well as the linear regression method both available in Statistical Analysis Software, version 9.4, were utilized.

The Pearson Correlation approach indicate significant positive correlation between wood density (WD) and ignition time (IT) and limiting oxygen index (LOI). That is to say that WD either rises or falls with both quantities. There is a significant negative correlation between wood density and flame propagation rate (FPR). It implies that wood density decreases with an increasing value of FPR and vice versa. These strong associations, otherwise called multi-collinearity, imply that one predictor variable can be linearly predicted from the others with a substantial degree of accuracy.

The principal components Analysis (PCA) suggest that the first three principal components explain approximately $80 \%$ of the data variability. This being a strong indication that the model dimensionality can be reduced to three regressors only. The regression step is used with the options R-square, Mallow's $C_{p}$, Akaike information criteria (AIC) and Bayesian information criteria (BIC) to select the most parsimonious model for wood density. Model selection reveal that the most parsimonious model for wood density has FPR, AGT and LOI as regressors with $R_{s q}=0.8678$.

In conclusion, wood density relates well with flame propagation rate, afterglow time and limiting oxygen index while ignition time, flame duration and ash formation do not show any straightforward relationship with wood density and therefore constitute noise. Okafor et al. (2020a) reported strong association between wood density and ignition time, flame propagation rate and limiting oxygen index in a pairwise-wise comparison. However, we note that ignition time disappeared in the final model due to multi-collinearity with flame propagation rate and limiting oxygen index.

\section{FUNDING}

This work was supported by Nnamdi Azikiwe University, Awka. The authors took the responsibility of the costs associated with the development and publishing of the current manuscript.

\section{CONFLICTS OF INTEREST}

VNO is employed by Nnamdi Azikiwe University, Awka, and receives salary as part of his employee remuneration. PUU is an employee of Nnamdi Azikiwe University, Awka, and receives salary as part of his employee remuneration. IE is an Associate of Biostatistics and programming Department, AB Science Pharmaceutical (Oncology), Paris. He receives salary as part of his employee remuneration.

\section{ACKNOWLEDGMENT}

The authors would like to thank the Nnamdi Azikiwe University for supporting the research.

\section{REFERENCES}

[1] M. Momo, A. N. Eboatu and E. G. Kolawole, Flammability of tropical woods - I. investigation of the burning parameters. Journal of Polymer Degradation and Stability, 54 (2-3), 403 - 411, 1996.

[2] B. M. Garba, A. N. Eboatu, and M. A. Atta-Elmannan, Note: Effect of flame-retardant treatment on energy of pyrolysis/combustion of wood cellulose, Fire and Materials, 18(16), 381- 383, 1994.

[3] C. Jennings, Fire Technology, Malaysia International Conference, 35 (1), 2000.

[4] D. Martin, M. Tomida and B. Meacham, Environmental impact of fire, Fire Science Reviews, 5 (5) ,1-21, 2016 
[5] L. A. Lowden and T. R. Hull, Flammability behavior of wood and a review of the methods for its reduction, Fire Sci. Rev., 2 (4), 2013.

[6] A. Adekunle, I. I. Umanah, K. E. Ibe and I. M. Rukewe, Statistical analysis of fire outbreaks in homes and public buildings in Nigeria: a case study of Lagos State, International Journal of Engineering Research and Advanced Technology, 4(8), 2018.

[7] A. I. Bartlett, R. M. Hadden, and L. A. Bisby, A review of factors affecting the burning behavior of wood for application to tall timber construction, Fire Technology, 55, 1-49, 2019

[8] A. N. Eboatu, I. Amanfo and I. O. Akpabio, Effect of flame-retardant treatment on the mechanical properties of some tropical timbers, Journal of Applied Polymer Science, 44, 39-242, 1992.

[9] A. N. Eboatu, S. M. Alhaji, and P. A. C. Okoye, Studies on fire tolerant timbers of Sudan Savannah, Journal of Thermal Analysis, 5, 07-211, 1995.

[10] N. H. Okoye, A. N. Eboatu, R. U. Arinze and O. A. Ogbonna, Effect of density on flame characteristics of some tropical timbers, IOSR J. Appl. Chem, 1, 104-111, 2014.

[11] V. N. Okafor, M. C. Obiadi, and J. N. Obiefuna, Correlations of major flame characteristics of some fire tolerant trees of South-East, Nigeria by coefficient of determination (R2), Journal of Scientific Research and Reports, 26 (4), 81 - 98, 2020.

[12] S. Wang, R. C. Little and D. L. Rockwood, Variation in density and moisture content of wood and bark among twenty Eucalyptus grandis progenies, Wood Science and Technology, 18, 97 - 100, 1984

[13] F. C. Meinzer, A. James, G. Goldstein and D. Woodruff, Whole-tree water transport scales with sapwood capacitance in tropical forest canopy trees, Plant, Cell \& Environment, 26 (7), 1147-1155, 2003.

[14] V. N. Okafor, U. W. Okafor, R. I. Anyalebechi, M. C. Obiadi, J. N. Obiefuna, C. P. Okonkwo and B. I. Tabugbo, Density effects and its relationship with major flame characteristics of selected fire tolerant trees in South-East Nigeria: a look at oven and sun-dried timbers, J. Chem. Soc. Nigeria, 45 (5), 852-862, 2020.

[15] S. Wold, K. Esbensen, and P. Geladi, Principal component analysis, Chemometrics and intelligent laboratory systems, 2 (1-3), 37-52, 1987.

[16] R. B. Cattell, The scree test for the number of factors, Multivariate behavioral research, 1 (2), 245-276, 1966.

[17] D. C. Montgomery, E. A. Peck, and G. G. Vining, Introduction to linear regression analysis, New York, John Wiley \& Sons; 2021

[18] H. Kopka and P. W. Daly, A Guide to $B T_{E} X$, 3rd ed. Harlow, England: Addison-Wesley, 1999. 